\title{
Effect of Methyl Ethyl Ketone (MEK) Organic Solvent Exposure on Incidence of Neurotoxicity in Shoe Manufacturing Workers
}

\author{
Denta Aditya Episana ${ }^{1 *}$, Aria Kekalih², Liem Jen Fuk ${ }^{3}$ \\ 1. Master of Occupational Medicine, Department of Community Medicine, Faculty of Medicine \\ Universitas Indonesia, Jakarta 10320 \\ 2. Division of Epidemiology and Biostatistics, Department of Community Medicine, Faculty of \\ Medicine Universitas Indonesia, Jakarta 10320 \\ 3. Division of Occupational Medicine, Department of Community Medicine, Faculty of Medicine \\ Universitas Indonesia, Jakarta 10320
}

*Coresponding Author : denta.episana@yahoo.com

\begin{abstract}
Background: Shoe manufacturing factory workers in developing countries are daily exposed to complex mixtures of organic solvents. Chemical exposure occurs through inhalation / respiration and skin which can affect many physiological systems. The main chemical exposure to organic solvents in shoe manufacturing comes from the process of gluing and cleaning process by using organic solvents on footwear in the assembling section. Methyl ethyl ketone is one type of organic solvent which, when entering into the body through inhalation routes can cause irritation of the nose, throat, lungs and chest becomes congested. Acute neurotoxicity is a collection of symptoms in the central nervous system (central nervous system depression, psychomotor disorders, narcosis, drowsiness, headache, dizziness, dyspepsia, and nausea).

Method: The research design was a prospective cohort research consisting of 45 people for each high MEK exposed group and low exposed to MEK. Data collection was done by interview, physical examination, MEK level measurement of pre-shift urine and end-shift work, and filling out questionnaires Form Acute symptoms rating questionnaire at the beginning of work shift (07.00), 2 hours after work (09.00), break (12.00), 2 hours after break (15.00), and end of work shift (16.00).

Result: The incidence of acute neurotoxicity symptoms in the MEK-high exposed group based on the Acute Symptoms questionnaire was $51.1 \%$. Age factor with symptoms of acute neurotoxicity in workers at PT. X with $p$ value $=0.432$, gender factor with $p$ value $=0.162$, education factor with $p$ value $=0.897$, nutritional status factor with $\mathrm{p}$ value $=0.865$, alcohol habit factor with $\mathrm{p}$ value $=0.181$, coffee drinking habit factor with $\mathrm{p}$ value $=0.265$, and smoking habit factor with $\mathrm{p}$ value $=0.968$, work duration factor with symptoms of acute neurotoxicity at worker in PT. X with $\mathrm{p}$ value $=0.533$, and the use factor of personal protective equipment (PPE) with $\mathrm{p}$ value $=0.470$. In this research, symptoms of acute neurotoxicity were dominant are fatigue $(80 \%)$, headache $(77.8 \%)$, nausea $(71.1 \%)$, dizziness $(66.7 \%)$, and feeling of intoxication $(53.3 \%)$.

Conclusion: There are no subject and occupational factors that have a significant effect to the symptoms of acute neurotoxicity. Conducting isolation of other work areas for workers exposed to chemicals that because of high potential to harm other workers in the vicinity. Reassessing the hazard risk of using MEK substitutes with other chemicals that are of lower risk or replace with water-based solvents. Provide PPE eligible to all workers exposed to chemicals and workers around them. A PPE fit test is used for workers to feel comfortable while wearing it, giving strict sanctions to workers who do not consistently use personal protective equipment.
\end{abstract}

Keywords: Methyl Ethyl Ketone, Acute Neurotoxicity, Shoe Manufacturing Workers. 


\section{Introduction}

Workers in shoe manufacturing factories in developing countries are exposed each day to complex mixtures of organic solvents. Chemical exposure occurs either through the inhalation / respiratory and the skin route and may affect many physiological systems. The main chemical exposure to organic solvents in shoe manufacturing comes from the process of gluing and cleaning process by using organic solvents on footwear in assembling sections. Because the use of these chemicals is applied by hand expertise and using a brush, the inhalation and skin become an important exposure route. Mixtures of chemicals include several types, one of which is methyl ethyl ketone. ${ }^{1}$

Methyl ethyl ketone is one type of organic solvent which, when entering the body through inhalation routes, can cause irritation of the nose, throat, lungs and chest to become tight. Skin contact causes irritation, redness, drying of skin and dermatitis. The more severe exposure of methyl ethyl ketone if inhaled, ingested or skin contact can cause neurotoxic symptoms such as headache, dizziness, fatigue, speech becomes unclear, decreased body temperature and coma. ${ }^{2}$

Methyl Ethyl Ketone (MEK) is a transparent, colorless, volatile, and flammable liquid with excellent properties and the fragrance described is light, fragrance, sharp, irritating, mint, like-acetone, sweet, and unpleasant (olfactory threshold $=16$ parts per million [ppm]), MEK will trigger an explosion when mixed with air or oxygen at concentrations of between $1.4 \%$ and $11.4 \% .^{3}$

Shoe manufacturing workers exposed to organic solvent Methyl Ethyl Ketone (MEK) at PT. X accounted for $38 \%$ of workers exposed to the chemical as a whole. Based on patient visit data from polyclinic in January December 2016, the result of data of the top ten diseases that dyspepsia, cephalgia and myalgia including experienced by the workers at PT. X. The high use of organic solvent Methyl Ethyl Ketone and the findings that the top ten diseases have the possibility to be associated with acute neurotoxicity due to exposure of MEK is the basis of researchers to examine the relationship between exposure effects of MEK organic solvents and other risk factors for acute neurotoxicity in workers at PT . X.

\section{Methods}

The design of this research used a prospective cohort method. The research was started at 07.00 WIB before working until 16.00 WIB after work and finished in one day. Research conducted at PT. X and the research was assisted by a treating doctor and a nurse who will assist in the selection of sample candidates into a sample of the research by doing a physical examination, and neurological examination. With inclusion criteria such as workers of PT. X is willing to participate in research with approval, workers who come to work at PT. X when selected as sample, willing to follow interviews, physical examination, and laboratory. Exclusion criteria such as subjects exposed Methyl Ethyl Ketone (MEK) outside working hours, examples of working part time in the informal industry, workers are performing outside tasks as the research progresses, workers with previous neurological disease history, such as epilepsy, stroke, head injury, previous neuropsychiatric history, history of drug user, history of diabetes and history of kidney disease.

Total 90 person as samples were involved, 45 employees with high exposed to organic solvent Methyl Ethyl Ketone (MEK) working on the assembling, second process, stockfitting and warehouse material area and 45 employees with low exposed to organic solvent Methyl Ethyl Ketone (MEK) on the assembling, finishing, warehouse material, cutting, sewing, pounching, embroidery area and then performed a biological examination of urine taken before work and after work.

The sample selection was performed by stratified systematic random sampling, the primary data collection was obtained at the time of the research before the work (07.00 WIB), two hours after work (09.00 WIB), at rest (12.00 WIB), two hours after the break (15.00 WIB), and after completion of work (16.00 WIB) performed by using the Acute symptoms rating questionnaire. Rating performed using the visual analogue scale (VAS, visual analogue scale) of 0-100 mm were assessed from "not felt at all" (0 mm), "hardly felt at all" (6 mm), "somewhat (26 mm), "rather" (48 mm), "quite" (71 mm), "very" (90 mm) and "almost unbearable" (100 mm). The questionnaire is described for inhalation exposure and has been used in several inhalation studies. ${ }^{4}$ Characteristics of respondents covering: identity (age, education, employment, workplace, and occupational history, smoking habits, drinking habits, drinking alcohol, other activities outside of working hours, history of head trauma, habitual use of personal protective equipment (PPE) and acute symptoms of neurotoxicity disorders. 
Secondary data collection was obtained from existing data in medical record files such as data on the job history, history of exposure, history of disease, and monitoring results of work environment MEK test. Dependent variable is symptomatic of acute neurotoxicity, and MEK Urine level on early shift (07.00 WIB) and end of work shift (16.00 WIB) and independent variable is MEK exposure level work environment, age, duration of employment, use of personal protective equipment (PPE), nutritional status, smoking status, smoking habit, alcohol habit, drinking coffee.

SPSS 20.0 version software package was used for statistical analysis. The Chisquared test with $\mathrm{p}<0.05$ was used for bivariate analysis. The research was conducted after obtaining approval from the Ethics Committee of Medical Faculty Universitas Indonesia.

\section{Results}

The employed population exposed to MEK = 312 and the unexposed methyl ethyl ketone (MEK) were 12,367 workers, scattered in D1, D2, D3, D4, D5, Second Process, Chemical Engineering, and Warehouse departments. MEK exposure then evaluated in the work environment, obtained the results of two groups namely MEK work environment (+), and MEK work environment (-).

Sampling was conducted by stratified systematic random sampling to meet the required number of samples in high exposure worker group MEK (Methyl Ethyl Ketone) and low exposure worker group MEK (Methyl Ethyl Ketone), 45 persons respectively. Measurement of MEK urine before work (pre shift) and after work (post shift) on April 25,
2017. Then the questionnaires were given to the respondents every two hours, that is at 07.00, $09.00, \quad 12.00,15.00,16.00$ WIB. The respondents who dropped out were 7 people because they did not give urine after 1 person and the amount of urine collected was less than the required amount $(30 \mathrm{cc})$. The addition of 7 people was held on May 2, 2017 in Low MEK Exposed group. Measurements of MEK Urine performed before work and after work are done by employee's urine collected into a pot which is then recorded by the laboratory team at the polyclinic. The urine sample was stored in a container of icebox with a storage temperature of $5^{\circ} \mathrm{C}$. Box container no preservatives because methyl ethyl ketone is stable. Labeling process was done manually, from the data carried by the sampling officer then got the label with the registration of the laboratory number. After that the samples were submitted to the laboratory workers and re-checked between the physical samples with the document handover carried by the sampling officer and done the process of labeling samples one by one with a label that has been registered by the service.

Questionnaires used in data collection include information sheet (informed consent), physical examination sheet of prospective respondents, characteristics form of the respondents, Questionnaire Acute Symptoms.

For each respondent who entered into the group of workers with high exposed to MEK and low exposed to MEK given a questionnaire. At the end of the sampling, the researchers classified the respondents of the exposure group of high exposed MEK and the low exposed MEK group. After 90 samples were obtained, the researchers performed an analysis of both groups.

Table 1. The incidence of acute neurotoxicity based on the Acute Symptoms Questionnaire

\begin{tabular}{|c|c|c|c|c|c|c|c|}
\hline \multirow[t]{3}{*}{ Exposed MEK group } & \multicolumn{4}{|c|}{ Acute neurotoxicity } & \multirow[t]{3}{*}{$\mathrm{p}$} & \multicolumn{2}{|c|}{ Total } \\
\hline & Yes & $(\mathrm{n}=42)$ & No & $(\mathrm{n}=48)$ & & & \\
\hline & $\mathrm{n}$ & $\%$ & $\mathrm{n}$ & $\%$ & & $\mathrm{n}$ & $\%$ \\
\hline High MEK & 23 & 51.1 & 22 & 48.9 & 0.398 & 50 & 50 \\
\hline Low MEK & 19 & 42.2 & 26 & 57.8 & & 50 & 50 \\
\hline
\end{tabular}

*Pearson Chi-Square Test

Table 1 show the incidence of acute neurotoxicity symptoms in the high exposed MEK group based on the Acute Symptoms questionnaire was $51.1 \%$. And the incidence of acute neurotoxicity symptoms in the low exposed MEK group was $42.2 \%$. Symptoms of acute neurotoxicity did not have a significant association in the high exposed MEK and low exposed MEK groups with $\mathrm{p}$ value $=0.398(\mathrm{p}>$ $0.05)$. 
IJCOM 2021 July;1(1):32-40

Table 2. The incidence of acute neurotoxicity symptoms based on the Acute Symptoms Questionnaire

\begin{tabular}{|c|c|c|c|c|c|c|c|}
\hline \multirow[t]{2}{*}{$\begin{array}{l}\text { Acute neurotoxicity } \\
\text { synptoms* }\end{array}$} & \multicolumn{2}{|c|}{$\begin{array}{l}\text { High } \text { MEK }^{\mathrm{O}} \\
\quad(\mathrm{n}=45)\end{array}$} & \multicolumn{2}{|c|}{$\begin{array}{l}\text { Low MEK } \\
(\mathrm{n}=45)\end{array}$} & \multirow[t]{2}{*}{$\mathrm{p}$} & \multicolumn{2}{|c|}{ Total } \\
\hline & $\mathrm{n}$ & $\%$ & $\mathrm{n}$ & $\%$ & & $\mathrm{n}$ & $\%$ \\
\hline \multicolumn{8}{|l|}{ Discomfort in the eyes } \\
\hline Yes & 45 & 50 & 45 & 50 & - & 90 & 100 \\
\hline \multicolumn{8}{|l|}{ Discomfort in the nose } \\
\hline Yes & 45 & 50 & 45 & 50 & - & 90 & 100 \\
\hline \multicolumn{8}{|l|}{$\begin{array}{l}\text { Discomfort in throat or } \\
\text { airways }\end{array}$} \\
\hline Yes & 45 & 50 & 45 & 50 & - & 90 & 100 \\
\hline \multicolumn{8}{|l|}{ Breathing difficulty } \\
\hline Yes & 45 & 50 & 45 & 50 & - & 90 & 100 \\
\hline \multicolumn{8}{|l|}{ Solvent smell } \\
\hline Yes & 45 & 50 & 45 & 50 & - & 90 & 100 \\
\hline \multicolumn{8}{|l|}{ Headache } \\
\hline Yes & 35 & 77.8 & 32 & 71.1 & 0.468 & 67 & 74.4 \\
\hline No & 10 & 22.2 & 13 & 28.9 & & 23 & 25.6 \\
\hline \multicolumn{8}{|l|}{ Fatigue } \\
\hline Yes & 36 & 80 & 32 & 71.1 & 0.327 & 68 & 75.6 \\
\hline No & 9 & 20 & 13 & 28.9 & & 22 & 24.4 \\
\hline \multicolumn{8}{|l|}{ Nausea } \\
\hline Yes & 32 & 71.1 & 25 & 55.6 & 0.126 & 57 & 63.3 \\
\hline No & 13 & 28.9 & 20 & 44.4 & & 33 & 36.7 \\
\hline \multicolumn{8}{|l|}{ Dizziness } \\
\hline Yes & 30 & 66.7 & 25 & 55.6 & 0.280 & 55 & 61.1 \\
\hline No & 15 & 33.3 & 20 & 44.4 & & 35 & 38.9 \\
\hline \multicolumn{8}{|l|}{ Feeling of intoxication } \\
\hline Yes & 24 & 53.3 & 22 & 48.9 & 0.673 & 46 & 51.1 \\
\hline No & 21 & 46.7 & 23 & 51.1 & & 44 & 48.9 \\
\hline
\end{tabular}

Note :

\section{* dependent variable \\ $\mathrm{O}$ independent variable}

Table 2 show the incidence of "Yes" answers each question of the 10 questions of the Acute Symptoms questionnaire as shown in Table 4.5. Basically the question is to see whether there are any irritative symptoms such as in the eye discomfort, nose, throat / breathing problems, difficulty breathing, and odor and acute symptoms of neurotoxicity on headache, fatigue, nausea, dizziness, . Of the five questions about the irritating symptoms all respondents answered 'Yes' in both groups of high MEK and MEK. In the next five questions about the symptoms of acute neurotoxicity, the highest "Yes" answer is in tired symptoms $(80 \%)$, followed by headache $(77.8 \%)$, feeling nauseated $(71.1 \%)$, dizziness rotating (66.7) $53.3 \%$ ). Symptoms of headache did not have a significant relationship significantly in the high MEK group and low MEK with $\mathrm{p}=0.468$ (p> 0.05 ), followed by fatigue with p value $=0.327$, feeling nauseated with $\mathrm{p}=0.126$, dizziness spin with value $\mathrm{p}=0.280$, a condition like a hangover with a value of $\mathrm{p}=0.673$. 
IJCOM 2021 July;1(1):32-40

Table 2. Effect of subject characteristic factor with symptoms of acute neurotoxicity

\begin{tabular}{|c|c|c|c|c|c|c|c|}
\hline \multirow[t]{2}{*}{ Factor } & \multicolumn{4}{|c|}{ Acute Neurotoxicity } & \multirow[t]{2}{*}{$\mathrm{RR}$} & \multirow[t]{2}{*}{$95 \% \mathrm{CI}$} & \multirow[t]{2}{*}{$\mathrm{p}$} \\
\hline & Yes & $\%$ & No & $\%$ & & & \\
\hline \multicolumn{8}{|l|}{ Age } \\
\hline$\geq 28$ years & 32 & 76.2 & 33 & 68.8 & 0.688 & $0.270-1.754$ & 0.432 \\
\hline$<28$ years & 10 & 23.8 & 15 & 31.3 & & & \\
\hline \multicolumn{8}{|l|}{ Gender } \\
\hline Female & 35 & 83.3 & 34 & 70.8 & 0.486 & $0.175-1.351$ & 0.162 \\
\hline Male & 7 & 16.7 & 14 & 29.2 & & & \\
\hline \multicolumn{8}{|l|}{ Educational level } \\
\hline $\begin{array}{l}\text { High school / } \\
\text { university }\end{array}$ & 31 & 73.8 & 36 & 75.0 & 1.065 & $0.412-2.749$ & 0.897 \\
\hline Elementary school & 11 & 26.2 & 12 & 25.0 & & & \\
\hline \multicolumn{8}{|l|}{ Nutritional status } \\
\hline Not obesity & 39 & 92.9 & 45 & 93.8 & 0.867 & $0.165-4.543$ & 0.865 \\
\hline Obesity & 3 & 7.1 & 3 & 6.3 & & & \\
\hline \multicolumn{8}{|l|}{ Alcohol Habits } \\
\hline No & 42 & 100 & 46 & 95.8 & 0.523 & $0.428-0.638$ & 0.181 \\
\hline Yes & 0 & 0 & 2 & 4.2 & & & \\
\hline \multicolumn{8}{|l|}{ Coffee Habits } \\
\hline No & 26 & 61.9 & 35 & 72.9 & 0.604 & $0.248-1.471$ & 0.265 \\
\hline Yes & 16 & 38.1 & 13 & 27.1 & & & \\
\hline \multicolumn{8}{|l|}{ Smoking Habits } \\
\hline No & 36 & 85.7 & 41 & 85.4 & 1.024 & $0.315-3.330$ & 0.968 \\
\hline Yes & 6 & 14.3 & 7 & 14.6 & & & \\
\hline
\end{tabular}

Table 2 show that it can be concluded there is with $\mathrm{p}$ value $=0.897$, nutritional status factor with $\mathrm{p}$ value $=0.865$, alcohol habit factor with no significant influence between the age factor with symptoms of acute neurotoxicity in workers at PT. $\mathrm{X}$ with $\mathrm{p}$ value $=0.432$, gender $\mathrm{p}$ value $=0.181$, coffee habit factor with $\mathrm{p}$ value $=0.265$, and smoking habit factor with $\mathrm{p}$ value factor with $\mathrm{p}$ value $=0.162$, education factor $=0.968$.

Table 3. Effect of work characteristic factors with symptoms of acute neurotoxicity

\begin{tabular}{|c|c|c|c|c|c|c|c|}
\hline \multirow[t]{2}{*}{ Factor } & \multicolumn{4}{|c|}{ Acute Neurotoxicity } & \multirow[t]{2}{*}{ RR } & \multirow[t]{2}{*}{$95 \% \mathrm{CI}$} & \multirow{2}{*}{$\mathrm{p}$} \\
\hline & Yes & $\%$ & No & $\%$ & & & \\
\hline \multicolumn{8}{|l|}{ Working period } \\
\hline$\geq 5$ years & 33 & 73.3 & 35 & 77.8 & 0.734 & $0.277-1.945$ & 0.533 \\
\hline$<5$ years & 9 & 21.4 & 13 & 27.1 & & & \\
\hline \multicolumn{8}{|c|}{$\begin{array}{l}\text { Personal protective } \\
\text { equipment (PPE) }\end{array}$} \\
\hline Inconsistent & 24 & 57.1 & 31 & 64.6 & 0.731 & $0.312-1.712$ & 0.470 \\
\hline Consistent & 18 & 42.9 & 17 & 35.4 & & & \\
\hline
\end{tabular}

* Pearson Chi-Square Test 
In table 3 can be concluded that there is no significant effect between the working period with symptoms of acute neurotoxicity with the $\mathrm{p}$ value $=$ 0,533 ( $p>0.05$ ), and the use factor of personal protective equipment (PPE) also has no significant relationship with symptoms of neurotoxicity acute with a $\mathrm{p}$ value $=0.470(\mathrm{p}>0.05)$.

\section{Discussion}

The design of this study is a prospective cohort that has advantages and limitations. The advantages of this prospective cohort design are that cohort studies are the best design in determining the incidence and course of disease or the effects studied. While the limitations are less efficient in time and cost, require long research time, and if there is a change in data collected by the respondent.

The problem of data result on methyl ethyl ketone (MEK) organic solvent measurements in urine lies at the level of purity and contaminants in other organic solvents used. Although MEK is the most organic solvent used in the shoe-making process, there is actually always mixing with other chemicals in relatively small amounts. In this study there was no analysis of food consumption in the respondents prior to the study, and the history of nail polish usage by women workers who assessed the effect of MEK on urine. The questionnaire has not been tested for validity but only a few adaptations to the changes in the questionnaire / face validity is to change the term "feeling intoxication" into a condition like a drunk to facilitate the respondents in understanding the questionnaire question.

Research that has been done on workers in shoe manufacturing factory PT. X exposed to MEK organic solvent obtained an incidence rate of $51.1 \%$ and results not much different in workers not exposed to MEK but found symptoms of acute neurotoxicity of $42.2 \%$. This difference is possible because of adjacent workplace design, no separation / there is no partition, and no work rotation that allows for chemical clearance. If this number is compared with some studies such as a study of 123 workers exposed to $52 \%$ methyl ethyl ketone organic solvent in high exposed workers and $41.3 \%$ are low exposed. ${ }^{5}$ A similar prevalence rate was found on 138 sample workers by assessing chronic neurotoxic symptoms in the study subjects of informal shoe industry workers with $55.8 \% .^{6}$ The prevalence rate of $76.5 \%$ of chronic neurotoxicity was obtained against 762 male workers in the printing company effect of exposed by organic solvent mixtures between n-hexane, toluene, isopropyl alcohol, and benzene. Another study conducted in Finland was $22.2 \%$ of workers with chronic neurotoxic symptoms from solvent exposure to the onset of chronic solvent encephalopathy in wood, paint, and metal industry workers. ${ }^{7}$ The prevalence in workers in the shoe industry is not much different, especially when compared to other countries where chemical hazard controls in the workplace are much more advanced. ${ }^{8}$

Based on symptoms of acute neurotoxicity taken from the Acute Symptoms questionnaire, the overall respondents in 90 people felt an uncomfortable complaint on the eyes, nose, throat. This clinical symptom effects not more than a few hours. In cases of acute poisoning caused by organic solvents, symptoms of irritation of the eyes and nose, throat and esophagus may occur at the onset of exposure, this condition may caused by high levels of exposure and long duration. Conditions that can increase this symptom are closed work sites without personal protective equipment, if ventilation flow is in the direction of the respiratory zone, or when products containing organic solvents are sprayed or applied in a warm working environment. ${ }^{9}$

In addition, solvent exposure in short duration can lead to lung dysfunction. Symptoms of mucous membrane irritation can occur in humans when exposed to 3-5 minutes by solvent. Excessive exposure or solvent levels above the threshold value may cause severe pulmonary edema and pulmonary obstruction with alveoli bleeding. ${ }^{10}$

The dominant symptoms of acute neurotoxicity was $80 \%$ fatigue, followed by $77.8 \%$ headache, $71.1 \%$ nausea, $66.7 \%$ dizziness, and $53.3 \%$ feeling of intoxication. This condition is consistent with feelings of motion sickness, dyspnea, nausea, headache, ataxia, is the worst case that can eventually cause myoclonus, confusion, drowsiness, coma and convulsions. ${ }^{9}$

In bivariate analysis on the characteristics of subjects and work characteristics it can be concluded that there is no significant influence of each factor on the symptoms of acute neurotoxicity.

Age $\geq 28$ years became dominant in $76.2 \%$ of respondents with symptoms of acute neurotoxicity. Age is a factor that affects the onset of disease due to exposure of chemicals that are neurotoxic. Even the diagnosis criteria of chronic neurotoxicity takes into account the age factor with a cut off of 28 years. Age becomes one that affects the cognitive functioning of the brain, in addition, that nerve cells have the ability to compensate for the toxic effects of chemicals, but along with increasing age it is also reduced so that the clinical manifestations of exposure to toxic materials will begin to appear, toxic also can make nerve cells susceptible to the influence of age. ${ }^{11}$

The sex factors described in the discussion of incidence are not statistically significant but when seen from the proportion of women showing symptoms of acute neurotoxicity is much more by $83.3 \%$. This is may caused by fat composition in women more than man, women have a higher percentage of body fat than men. In addition, women 
store more fat in the gluteal-femoral area, while men store more fat in the abdominal area. ${ }^{12}$

Organic solvents are lipophilic, meaning fat soluble chemicals, which is why women are more susceptible than men. In addition work, the core tasks of women are give birth, parenting and taking care of household. Apart from the provision of health services and hygienic measures, it includes activities such as food purchases and other products for daily life, for childcare and housecleaning. This shows women are more exposed to other types of chemicals than men. If women are consumers of harmful chemicals in the products they buy, this contributes to making women more prone to experience symptoms of neurotoxicity than men. ${ }^{13}$

The educational factor was not statistically significant for the symptoms of acute neurotoxicity. In this study, the proportion of those with higher education or equivalent of high school or university indicates that the higher level of education is not much different feel the symptoms of acute neurotoxicity or not. This may caused by the shoemaking technology does not require high academic skills, it is necessary that skills or skills in a class that will usually be easy to master if the worker has enough experience.

The nutritional status factor was not statistically significant. But theoretically those who belong to the more nutritional status group are considered to have more fatty tissue so that organic solvents that are generally lipophilic will have much retention, consequently the neurotoxic symptoms will occur more frequently caused by the MEK exposure levels received by the worker. Chemicals have one common characteristic, all of which are lipophilic. A lipophilic or low level hydrophilic combination can be agent for the induction of neurological disease and metabolic diseases, diabetic and obesity. ${ }^{14}$

Organic solvents are absorbed by organs with high blood perfusion and high lipid (fat) contents, such as the liver, kidneys and brain. Organic solvents are excreted through the kidneys or lungs. The decomposition process is calculated in half-life: the time taken between the last exposure to the substance and when the concentration has decreased by half. Organic solvents usually have a short half-life in the blood, but a longer half-life in adipose tissue. Solvent has a half-life of three hours in the blood but 2 or 3 days in adipose tissue. This means that daily exposure to toxic substances continues to increase its concentration in adipose tissue. This is exacerbated by obesity, because the larger amount of adipose tissue means more substances being taken, prolonging the life of the beak effectively. Simultaneous exposure of some solvents, or a combination of exposure and use of drugs or alcohol may also prolong the half-life. ${ }^{15}$

Habit factors such as alcohol, coffee drinking, and smoking in the study did not show statistically significant associations, in addition to the amount of habits that are not many, other things also because $83.3 \%$ of respondents are women workers, especially in Indonesia in general have no such habits. Smoking habits can adversely affect lung function, while the main path of organic solvent entering the body is through inhalation. besides cigarette smoke contains many chemicals such as benzene, carbon monoxide, hydrogen cyanide, and cadmium. The presence of such chemicals in cigarette smoke can be a source of error in evaluating the biological monitoring results in workers who are smokers. (Jefferson F, Michael B., 2000). The combination of two chemical toxins can cause adverse effects, a phenomenon called synergism, and potentiation should be considered when examining exposure to a complex mix of toxic compounds such as those found in contaminated drinking water, smoke from cigarettes, forest fires and smoke from hazardous waste sites . 16

Caffeine in coffee is diuretic, it can affect the results of biological monitoring is also a stimulant and affect sleep rhythm. Excessive drinking of coffee can cause withdrawal syndrome, which is characterized by lethargy, irritability, and pain. Alcohol can suppress the central nervous system, in addition it can also be neurotoxic to nerve cells. Drinks containing ethanol can MEK metabolism so that it will increase MEK levels in the air and in the urine ${ }^{17}$

In this study found the prevalence of workers exposed by MEK is $54.8 \%$. This is consistent with the finding of a close correlation between MEK environmental air concentration and urine concentration at the end of work shift from MEK and acetylmethyl carbinol (AMC). The mean exposure level of $101 \mu \mathrm{g} / 1$ [standard deviation (SD 67)], MEK excretion in urine was $487 \mu \mathrm{g} / 1$ (SD 277), and the AMC concentration was $645 \mu \mathrm{g} / 1$ (SD 354). Very few MEK levels are detected in the urine during preshift, but concentrations increase rapidly during exposure, related to ambient air concentration but, only $0.1 \%$ of excreted MEK is maintained unchanged in the urine. ${ }^{18}$

MEK is also the natural constituent of many food products, in all food groups (fruits and vegetables, milk, meat, and grains). In addition, secbutanol also occurs naturally in many foods. Secbutanol is metabolised rapidly into MEK in humans, and consumption of foods containing sec-butanol may cause MEK levels in plasma. ${ }^{17}$

This is possible to be found in 39 respondents at the measurement of urinary MEK before work found MEK levels of positive urine range $0.07-1.00 \mathrm{mg}$.

The working period factor in this study was not statistically significant. The period of work is not always the same as the length of exposure because many of the workers often change jobs, where each 
type of work is not always the same as the exposure factor. Neurobehavioral function deficits can be detectable at moderate concentrate exposure durations more five years. Exposure to moderate concentrations is approaching threshold exposure, Threshold Limit Values-Time Weighted Average, TLV-TWA, or approaching 1 using regulatory additions to ACGIH over five years mixed exposure. More recent defects in neurobehavioral function can be detected after a 10-year solvent exposure time.

Based on Evan in determining diagnostic criteria in chronic neurotoxicity because of intense solvent exposure, expected duration of exposure beyond 10 years will show symptoms, whereas longer time for low exposure will appear symptoms of neurotoxicity. Determination of solvent exposure duration more than five years or 10 years is not an issue, but the history of concentration of exposure is often debated. ${ }^{19}$

The use of personal protective equipment (PPE) in this study did not show statistically significant relationship. However, from the data it appears that workers who do not have a habit of using PPE consistently percentage of symptoms of acute neurotoxicity is higher, $83.3 \%$ than that using a respirator consistently. Causes of the reluctance to use PPE because of poor worker consciousness in favor of the use of PPE, they feel uncomfortable, and difficult to breathe when using it, among others, because the material used is not suitable for a hot and humid tropical climate despite repeatedly given training material.

\section{Conclusion}

From the results of research on 90 workers in shoe manufacturing company PT. X concluded that the incidence of acute neurotoxicity symptoms in high exposed group of MEK based on Acute Symptoms questionnaire was $51.1 \%$. And the incidence of acute neurotoxicity symptoms in the low MEK exposed group was $42.2 \%$. MEK organic solvent exposure does not affect the symptoms of acute neurotoxicity in workers at PT. X. And in this study, the dominant symptoms of acute neurotoxicity were easily tired $(80 \%)$, headache $(77.8 \%)$, feeling nausea $(71.1 \%)$, dizziness spin $(66.7 \%)$, and drunk condition $(53.3 \%)$.

Other factors are divided into the characteristics of the subject and the work can be concluded that there is no significant influence between the age factor with symptoms of acute neurotoxicity in workers at PT. $\mathrm{X}$ with $\mathrm{p}$ value = 0.432 , gender factor with value $\mathrm{p}=0.162$, education factor with value $\mathrm{p}=0.897$, nutritional status factor with $\mathrm{p}$ value $=0.865$, alcohol habit factor with $\mathrm{p}$ value $=0.181$, coffee habit factor with $\mathrm{p}$ value $=$ 0.265 , and smoking habit factor with $\mathrm{p}$ value $=$ 0.968 , working period factor with symptoms of acute neurotoxicity in workers at PT. $\mathrm{X}$ with the $\mathrm{p}$ value $=0.533$, the use of personal protective equipment $(\mathrm{APD})$ with the $\mathrm{p}$ value $=0.470$.

\section{Acknowledgements}

We sincerely thank the division of Occupational Medicine, Department of Community Medicine, Faculty of Medicine Universitas Indonesia and also the chairman of PT. X, Tangerang, Banten for accommodating and encouraging this research.

\section{References}

1. Todd L, Puangthongthub ST, Mottus K et al. (2008). Health Survey of Workers Exposed to Mixed Solvent and Ergonomic Hazads in Footwear and Equipment Factory Workers in Thailand. J Ann. Occup. Hyg. 52(3):195-205.

2. Foxall K. (2010). Methyl Ethyl Ketone General Information. Health Protection Agency, 1:1-4.

Jefferson F, Michael B. (2000). The Chemical Constituents in Cigarettes and Cigarette Smoke: Priorities for Harm reduction. A Report to the New Zealand Ministry of Health, 1-65.

3. National Research Council of The National Academies. (2011). Acute Exposure Guideline Levels For Selected Airborne Chemicals. Volume 10, 146-152.

4. Ernstgard L, Gullstrand E, Lof A, Johanson G. (2002). Are Women More Sensitive Than Men To 2-propanol Than m-xylene vapours? Occup Environ Med, 59:759-767.

5. Ampulembang J. (2004). Hubungan Pajanan Pelarut Organic Metil Etil Keton Terhadap Timbulnya Gejala Dini Neurotoksik Pada Pekerja di Perusahaan Sepatu "X" [Tesis] Jakarta: Universitas Indonesia.

6. Lelitasari. (2006). Hubungan Pelarut Organik Dengan Gejala Neurotoksik Pada Pekerja Alas Kaki Di Sektor Informal Ciomas Bogor (Menggunakan Kuesioner Swedish Q16) [Tesis] Jakarta: Universitas Indonesia.

7. Mezni, Ben Jemma. (2011). Chronic Solvent Encephalopathy in a Printing Unit for Flexible Packaging, Chapter

8. Keski-Santti. (2010). Occupational chronic solvent encephalopathy in Finland 1995-2007: incidence and diagnostic methods. Finnish Institute of Occupational Health, 83:6. 703-712.

9. Viaene MK. (2002). Overview of the neurotoxic effects in solvent-exposed workers. Arch Public Health, 60:217-32.

10. Kamal N, Haji B, Faheem M, Mohammad A. (2015). A Review of Environmental and Occupational Exposure to Xylene and Its Health Concerns. EXCLI Journal, 14:1167-186.

11. Roberto C, Nancy AD. (2013). Frontal Lobes and Aging: Deterioration and Compensation. 
Principles of Frontal Lobe Function. Oxford University Press.

12. Ellen B. (2001). Gender differences in fat metabolism. Curr Opin Clin Mutr Metab care, 4:499-502.

13. Alexandra C, Johanna H. (2016). Women and Chemicals The impact of hazardous chemicals on women. Women in Europe for a Common Future.

14. Liira J, Johanson G, and Riihimaki V. (1990). Dose-dependent kinetics of inhaled methylethylketone in man. Toxicol. Lett, 50(23):195-201.

15. Wekking EM, van Houst MSE, van der Iaan G. (2004). Behavioural neurotoxicology. Deelman B, Eling $\mathrm{P}$, de Haan E, van Zomeren E (Ed): Klinische neuropsychologic. Amsterdam, Boom, 462-81.
16. Chemistry, Emission Control, Radioactive Pollution and Indoor Air Quality, Dr. Nicholas Mazzeo (Ed.). InTech. Croatia, 429-46.

17. American Chemistry Council Ketones Panel. (2003). Methyl Ethyl Ketone (CAS No. \&8-93-3), ExxonMobil Biomedical Sciences, 1-130.

18. Perbellini L, Brugnone F, Mozzo P, Cocheo V, and Caretta D. (1984). Methyl Ethyl Ketone Exposure In Industrial Workers. Uptake and Kinetics. Int Arch Occup Environ Health, 54(1):73-81.

19. Evan D. (1998). Chronic Organic Solvent Neurotoxicity: Diagnostic Criteria. Occupational Safety and Health Service, Department of Labour, $1-15$. 